\title{
Poleward bound: adapting to climate-driven species redistribution
}

\author{
Jess Melbourne-Thomas $(\mathbb{D} \cdot$ Asta Audzijonyte - Madeleine J. Brasier • \\ Katherine A. Cresswell • Hannah E. Fogarty • Marcus Haward • \\ Alistair J. Hobday • Heather L. Hunt - Scott D. Ling • Phillipa C. McCormack • \\ Tero Mustonen - Kaisu Mustonen • Janet A. Nye • Michael Oellermann • \\ Rowan Trebilco • Ingrid van Putten • Cecilia Villanueva • Reg A. Watson • \\ Gretta T. Pecl
}

Received: 10 April 2020/ Accepted: 27 January 2021/Published online: 29 March 2021

(C) Crown 2021

\begin{abstract}
One of the most pronounced effects of climate change on the world's oceans is the (generally) poleward movement of species and fishery stocks in response to increasing water temperatures. In some regions, such redistributions are already causing dramatic shifts in marine socioecological systems, profoundly altering ecosystem structure and function, challenging domestic and international fisheries, and impacting on human communities. Such effects are expected to become increasingly widespread as waters
\end{abstract}

Supplementary Information The online version contains supplementary material available at https://doi.org/10.1007/ s11160-021-09641-3.

J. Melbourne-Thomas $(\bowtie) \cdot$ K. A. Cresswell ·

A. J. Hobday · R. Trebilco · I. van Putten

CSIRO Oceans and Atmosphere, Hobart,

TAS, Australia

e-mail: Jess.Melbourne-Thomas@csiro.au

J. Melbourne-Thomas · A. Audzijonyte ·

H. E. Fogarty · M. Haward · A. J. Hobday ·

P. C. McCormack · R. Trebilco · I. van Putten .

C. Villanueva $\cdot$ G. T. Pecl

Centre for Marine Socioecology, University of Tasmania,

Tasmania, Australia

A. Audzijonyte $\cdot$ M. J. Brasier $\cdot$ K.

A. Cresswell · H. E. Fogarty · M. Haward .

S. D. Ling · M. Oellermann · C. Villanueva .

R. A. Watson - G. T. Pecl

Institute for Marine and Antarctic Studies, University of

Tasmania, Hobart, TAS, Australia continue to warm and species ranges continue to shift. Actions taken over the coming decade (2021-2030) can help us adapt to species redistributions and minimise negative impacts on ecosystems and human communities, achieving a more sustainable future in the face of ecosystem change. We describe key drivers related to climate-driven species redistributions that are likely to have a high impact and influence on whether a sustainable future is achievable by 2030 . We posit two different futures-a 'business as usual' future and a technically achievable and more sustainable future, aligned with the Sustainable Development Goals. We then identify concrete actions that provide a

\author{
H. L. Hunt \\ Department of Biological Sciences, University of New \\ Brunswick, Saint John, NB, Canada \\ P. C. McCormack \\ Faculty of Law, University of Tasmania, Hobart, \\ TAS, Australia \\ T. Mustonen $\cdot$ K. Mustonen \\ Snowchange Cooperative, Lehtoi, Finland \\ J. A. Nye \\ Institute of Marine Sciences, University of North Carolina \\ At Chapel Hill, Morehead City, NY, USA \\ M. Oellermann \\ Aquatic Systems Biology Unit, Technical University of \\ Munich, Freising, Germany
}


pathway towards the more sustainable 2030 and that acknowledge and include Indigenous perspectives. Achieving this sustainable future will depend on improved monitoring and detection, and on adaptive, cooperative management to proactively respond to the challenge of species redistribution. We synthesise examples of such actions as the basis of a strategic approach to tackle this global-scale challenge for the benefit of humanity and ecosystems.

Keywords Climate change - Future seas . Indigenous knowledge $\cdot$ Interdisciplinary $\cdot$ Range shifts $\cdot$ Species redistribution

\section{Introduction}

Species redistribution is a pervasive and extensive impact of climate change on marine ecosystems, with an estimated $25-85 \%$ of marine species having already shifted at least part of their geographical range (based on regional-scale studies: Dulvy et al. 2008; Pinsky et al. 2013; Wernberg et al. 2011), moving at an average rate of $\sim 70 \mathrm{~km}$ per decade (Poloczanska et al. 2013). Model projections indicate that such movements are likely to continue in the future (Cheung et al. 2016), with consequences for coastal communities, fisheries and ecosystem services, and for ocean management and governance (Pecl et al. 2017; Pinsky et al. 2018; Scheffers and Pecl 2019) (Fig. 1). While the evidence of climate-driven range shifts is substantial, with over 12,000 marine and terrestrial species worldwide documented to be shifting (Lenoir et al. 2019), the implications for ecosystem structure and function and for human societiesincluding potential adaptation responses - are not well understood.

Climate-driven range shifts in the marine environment have the potential to affect productivity, foodweb structure, the dominance and function of biogenic ecosystem engineers, as well as local and regionalscale biodiversity and ultimately human well-being (Pinsky et al. 2020). Some of these effects have already been documented (see review by Pecl et al. 2017), for example, the range extension of a tropical Diadematid sea urchin to temperate reefs with subsequent overgrazing leading to cascading ecosystem change for coastal kelp forest communities (Ling
2008; Ling and Keane 2018). In the Arctic, range shifts are profoundly altering ecosystem function, with larger, longer lived piscivorous species rapidly replacing fish communities that were primarily composed of smaller bottom-dwelling species (Frainer et al. 2017). While the extent of climate-driven range shifts in Antarctic marine ecosystems are less well described, there is increasing evidence that such shifts are occurring for multiple species (Melbourne-Thomas 2020). Changes in the distribution of key fisheries species are already exacerbating existing or creating new conflicts within and between countries (Belhabib et al. 2016; Pomeroy et al. 2016; Spijkers et al. 2018). Moreover, the impacts of climate-driven changes in species distribution are further compounded by the human-driven spread of invasive species (Mustonen et al. 2018). Our understanding of the overall scope and role of present change is also obscured by the fact that in many cases, changes may have already occurred and/or baselines have not been documented (Clavero 2014; Hobday 2011).

Ongoing species, community and ecosystem-level changes due to range shifts will challenge or even invalidate assumptions regarding biomass targets, reference points and the extent of fishable habitat (e.g. Ling and Keane 2018) and will therefore require substantial changes to fisheries management, including assessments, allocations and ecosystem considerations. There is also a regional disparity in outcomes for human systems emerging as species move towards polar regions and away from tropical regions (Cheung et al. 2009, 2010; Oremus et al. 2020) where human communities have a high level of dependence on coastal resources and often less adaptive capacity (Allison et al. 2009). Many people in tropical countries are very dependent on fishing for livelihoods and may not have the capacity or desire to move elsewhere. Preexisting regional tensions can also increase the risk of conflicts amongst fishery area users and authorities (Belhabib et al. 2018).

Further dimensions of this challenge include that species redistribution can lead to (and in some cases has already resulted in) the emergence of new fisheries that cross jurisdictional boundaries within and between countries and/or in international waters, requiring the negotiation of new agreements (Mustonen et al. 2018; Pinsky et al. 2018). Indirect effects of species range shifts on fisheries include changes in the distribution of diseases (Shields 2019) and of 


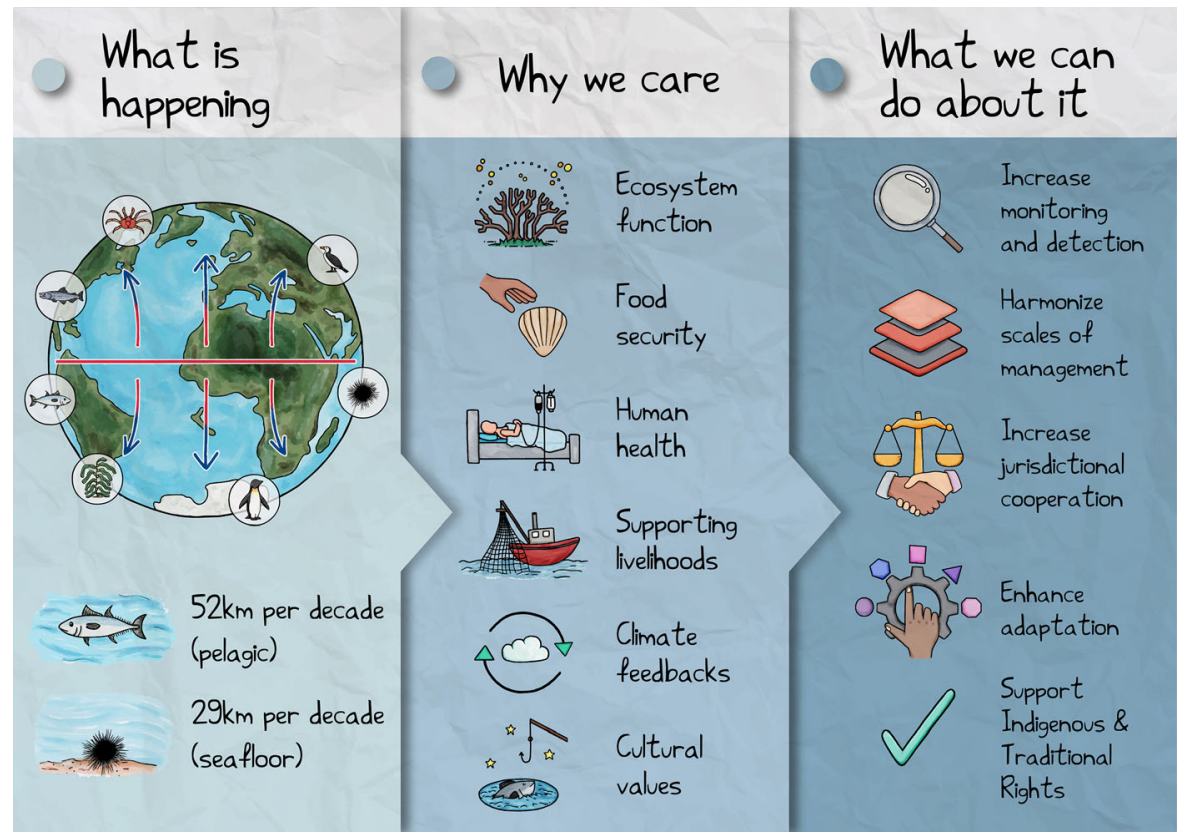

Fig. 1 The global challenge of climate-driven marine species redistribution

protected species that then have implications for management. An example of the latter effect is that climate-driven shifts in the habitat use of the North Atlantic Right Whale (an endangered species) among several important feeding grounds have resulted in mortality of whales from ship strikes and gear entanglement in areas where whales were previously uncommon. This has prompted the Canadian Government to limit vessel speeds and close fisheries in areas where the whales are now observed at key times in an attempt to avoid these mass mortality events (MeyerGutbrod et al. 2018a).

The disruption of cultural connections to iconic species and Indigenous fisheries-as those species move away from their traditional ranges-is an important issue that requires further consideration (Pecl et al. 2017) (Table 1). Indigenous connections to the sea and to marine species are deep, often profound (Mustonen et al. in prep) and developed over extensive time (Fischer et al. 2020). From an Indigenous perspective, the seen and the unseen non-humans occupying the coasts and marine ecosystems have coevolved with humans over thousands of years. Climate-induced changes not only disrupt the physical habitats but tear apart spiritual-cultural connections to these places and species (Table 1) (see the female spiritual guardians and change for the Haida Nation in Williams-Davidson 2017).

Species redistribution poses local to global-scale challenges for governance regimes that will require flexibility, cooperation and re-negotiation (Scheffers and Pecl 2019; Spijkers and Boonstra 2017; Spijkers et al. 2018). Scenario development is a useful tool to consider how these challenges might evolve into the future, and to consider alternative and complementary options for addressing them. While scenario development may take a number of different forms (Francis et al. 2011), scenarios can generally be categorised as: (1) predictive scenarios (identifying what will happen in the future based on current evidence, conceptualised as the probable future), (2) normative scenarios (focused on describing what we would like to happen, conceptualised as the preferable future) and (3) exploratory scenarios (which explore what could feasibly happen, conceptualised as the possible future) (Amara 1984; Börjeson et al. 2006). Normative and exploratory scenario approaches are likely to be particularly useful in the context of the oceans and climate-driven species redistribution due to the complexities and uncertainties associated with governance of sovereign and common-pool resources both at the national and international level (Nash et al. 2020). Notably, while scenario tools provide us with a vision 
Table 1 Indigenous and traditional cosmologies and species on the move

Indigenous and traditional communities witness climate-driven species on the move, with their extension into new areas and disappearance from others, around the world. This may have very practical implications - the lack of sea ice and expansion of cod in Western Greenland, for example in Attu and Aasiaat, has altered the local socio-economic patterns away from hunting and into fisheries. Especially for the cryosphere-dependent hunting societies (Mustonen and Mäkinen 2004), the rapid changes and species shifts polewards to the north are dramatic in scale, quantity and implications (Tunon 2018).

What has been often missing from the debates on the ways oceans are changing are the deeper levels of impacts and implications, as well as interpretations of species on the move and regime shifts of the seas for the Indigenous and traditional communities. For example, for the traditional Baltic sea seal hunters the knowledge of ice and snow is reflected in dozens of regional concepts related to traversing the ice fields, sometimes for 10 weeks unassisted (Mustonen and Mäkinen 2004). If ice conditions are lost such Indigenous and traditional knowledge repositories are lost as well. This makes the climate change and species on the move issues also questions of intangible cultural heritage losses.

Haisla author Eden Robinson from the West Coast of Canada has summarized interdependence of marine species and Indigenous peoples using the example of the eulachon (Thaleichthys pacificus or candlefish) and her people: "if the eulachon don't return to our rivers, we lose more than a species. We lose a connection with our history, a thread of tradition that ties us to this particular piece of the earth, that ties our ancestors to our children." (Robinson 2008: 215).

Alaskan Yupiaq educator, Elder and knowledge holder, the late Oscar Kawagley explained in the Convention on Biological Diversity CBD Article 8j Workshop in Helsinki, Finland in February 2008 that "all will have to be learned anew" (Mustonen 2008). With this Mr. Kawagley implied that as the new species and non-human beings arrive to the Indigenous home coasts and replace or co-inhabit the new novel ocean ecosystems on which these communities depend, the speed of change and implications are so big that the whole underlying knowledge-practice-belief of Indigenous ways of being has to be revised and reflected on. Central to Indigenous ways of knowing are the songs and reciprocal relationships between specific species and human societies. This may start a-new, with unknown species arriving to a particular location.

To illustrate this further, in Taiwan's Tao people's oral tradition of storytelling, there is the teaching of mavaheng so panid (the noble black-wing flying fish, Hirundichthys rondeletii) to the ancestors of Tao people. The teaching includes two major parts: first the inter-species pact for the survival and sustenance of peoples and fish, and the eco-calendar ahehep no tao that defines the arrangement of works and ceremonies all around the year. Secondly there is the knowledge about migratory fish, species of flying fishes and their predators for harvest, and way of eating. For example, some species should not be roasted and some should never be cooked together (Mustonen et al. In prep).

Unfortunately, these present and future revisions to knowledge can only happen from the inside of the culture. Of course, outside messages, reports and key observations can inform the "new pathfinding" under way in the global Indigenous and traditional communities. However, these changes often happen in the middle of many other (imposed) drivers of life-altering change, including loss of coastal land and resources, rapid cultural loss and sometimes even military and violent pressures against coastal communities. It is only rarely that an Indigenous community would have the rights, time and place to develop an informed understanding of the climate-induced marine changes occurring in the middle of the cacophony of everything else under way.

Another discourse within the Indigenous cosmologies and knowledge holders, based on publicly made statements and prophecies (see for example Simpson 2008), is that the perceived, present global change (of 'never-before-seen proportions' within science and modernity) has been actually known about by those Indigenous knowledge holders who are deeply rooted in their particular cosmologies and deep immersions with the world. Earth has shifted in the past too. Common to these narratives is that we are undergoing a massive global cleansing of Earth, as a transitory process towards a new era and epoch of the planet, perhaps an age of turbulence, chaos and massive system change, but one that will ultimately result in a new period, already seen and shown only to a handful of these knowledge holders (who have seen what the world will look like in the future). This narrative has been made public in the North American Indigenous communities (Simpson 2008), as well as for example in the Eurasian North with the Evenki (Mustonen 2009). Indigenous scholar Leanne Simpson (2008) calls this the global awakening of the $8^{\text {th }}$ fire for Indigenous Peoples.

Around the world, local communities are taking a range of actions that include preserving what they can, and re-learning the present and the future of marine species on the move by strengthening their community actions and presence in their home areas. For example, the local communities around lake Saimaa, Finland are plowing artificial, man-made snow nests for the Saimaa ringed seal, a freshwater seal which is dependent on ice cover for being able to reproduce and give birth safely. Snow dens are required for the pups on the first weeks of their existence due to the harsh open conditions on the lake ice and for their mothers to nurture their pups to adulthood. Climate change is causing major losses to this boreal environment where both the lake ice and the snow conditions are being lost. The development of artificial dens for the Saimaa seal is supporting this unique marine mammal population of only 400 individuals that has adapted to the freshwater in the European North.

On the coasts of the East Siberian Sea, the Indigenous Chukchi who utilize the coast line and the adjacent deltas for their fisheries in the High Arctic in the Russian North, have decided to stay on country and form new relationships to the loss of sea ice, melting permafrost and increased maritime traffic and natural resources extraction by choosing to maintain their presence and their life in the traditional territories (ELOKA 2019; Mustonen 2009). 
Table 1 continued

Much will change. The old ways of knowing the currents, sea ice and the certain mainstay species in various mythicalcosmological ways will be impacted. In some cases this will result in die-off events for species and direct worsening of Indigenous and traditional community food security, culture and existence. This cannot be avoided and much of it happens already at present. However, nobody knows the exact, final outcome of the present marine change and species re-organisation.

As the old world withers and dies away a new one will form, with new relationships and perhaps, just perhaps, a new resurgence and possibilities for the marine Indigenous and traditional communities embedded in their habitats, maintaining cosmic and mythic orders, as they have always done and strive to continue to do.

of a future, to drive change there needs to be a process for developing pathways to achieve that future. This requires the design and implementation of complementary and coordinated actions across all levels of society from local community groups to national governments and international organisations, and a process for adaptive learning (Boschetti et al. 2020).

In this paper we summarise available evidence and envisage what the phenomenon of climate-driven species redistribution means for marine social-ecological systems in the coming decade under two different scenarios: a business as usual future and a technically possible and more sustainable future. We then consider what steps towards a more sustainable future are technically feasible for our current society and may assist in achieving the Sustainable Development Goals (United-Nations 2015), minimising negative outcomes and capitalising on new opportunities. We chose a 10-year time-frame consistent with the UN Decade of Ocean Science for Sustainable Development (2021-2030), which clearly articulates the urgent need for adaptation strategies and scienceinformed policy responses to global change.

\section{Approach for developing scenarios and pathways}

We used the approaches described in Nash et al. (2020) to consider key assumptions, develop scenarios and identify possible pathways to alternative futures for the challenge of climate-driven species redistribution in the oceans. This approach was an iterative forecasting-hindcasting process (Fig. 2) involving expert elicitation and consultation through a series of workshops and meetings. The process included the interdisciplinary author team, which comprises law, governance, management, socioecological, climate

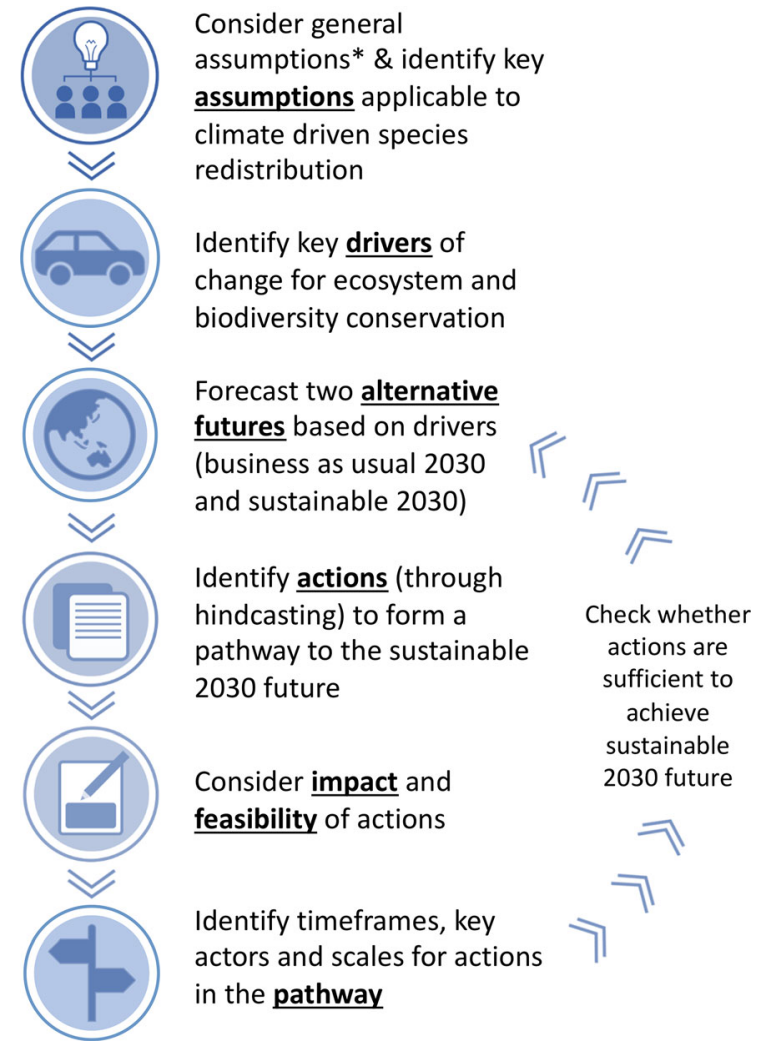

Fig. 2 An overview of the methods followed to develop alternative scenarios of 2030 for responding to the challenge of climate-driven species redistribution (* from Nash et al 2020)

science and economics experts, and Indigenous leadership. The team also consulted with an international group of Traditional Owners and Indigenous knowledge holders, and community representatives (see Mustonen et al. in prep and Fischer et al. 2020 for more details).

Specifically, we first identified the nature of the challenge (as outlined in the introduction of our paper 
above) and evaluated how the set of key assumptions underlying scenario development for 2030 ocean futures, as articulated by Nash et al. (2020), were relevant for the challenge of climate-driven species redistribution. The key assumptions described by Nash et al. (2020) are: (1) human populations will continue to increase; (2) the globe is locked into a certain amount of climate change within 10 years; (3) no new major international agreements are started; (4) no large-scale conflicts emerge; and (5) resource use and knowledge production continues. We also assumed that (6) projected trends in global-scale marine species redistribution and ocean animal biomass (as described by Cheung et al. 2009; Lotze et al. 2019) will occur on the time-scale of our study (from 2021 to 2030), which is consistent with observed marine species range shifts to date (Poloczanska et al. 2013; Sunday et al. 2012), and that (7) no new pandemics emerge in the coming decade.

We brainstormed a list of drivers, i.e. factors that are key to addressing the challenge of marine species redistribution and that may influence what future we can achieve over the course of the Decade for Ocean Science (see Table S1 for a complete list of these drivers). We then condensed this list into a manageable set of 'umbrella' drivers (by grouping related drivers from our list; see Nash et al. 2020) and used expert judgement in a workshop setting to select those umbrella drivers with both a high degree of impact on how we manage species redistribution and over which society has a relatively high degree of influence, at least over the 2021-2030 timeframe (see Nash et al.
2020 for full details). For each of these high-impact high-influence umbrella drivers (Fig. 3) we used literature review and forecasting to develop evidence-based descriptors for their status under current conditions (i.e. the recent past, approximately 5-10 years), under a 'business as usual' 2030 future and for a more sustainable (and technically possible) 2030 future, aligned with achieving the Sustainable Development Goals. From the descriptions of driver status for these two futures, we developed two alternative narrative scenarios for the year 2030 .

We then developed a set of actions related to each driver that, together, could constitute a pathway to shift the trajectory away from the 'business as usual' and toward the more desirable/optimistic 'sustainable' future. We considered by whom, by when and at what spatial scale each of these actions would need to be enacted to realise the more sustainable 2030 future. These steps were undertaken through a combination of expert input from the author team (in a workshop setting) and literature review. We also used expert judgement (i.e. all authors independently assigned scores to action) to rate the feasibility and impact of each action, and used an iterative approach (with feedback between the scenarios and our development of pathways) to evaluate whether these actions, in tandem, would be sufficient to realise the more sustainable 2030 future for climate-driven species redistribution, as we had envisaged it (Fig. 2).

We acknowledge that the disruptions of 2020-2021, in particular the COVID-19 pandemic, are currently causing major changes to economies and socioecological systems at the global scale. The

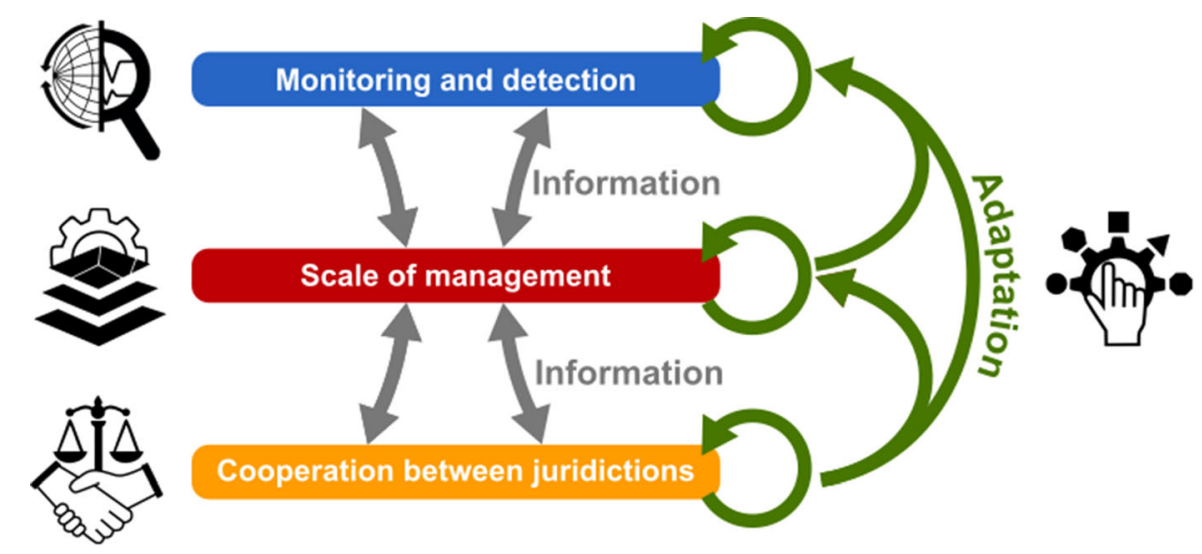

Fig. 3 Key drivers that will shape future outcomes of species redistribution 
business as usual scenario we describe is based on evidence from the recent past before the pandemic, and assumes a general return to this trajectory in the next few years. The changes elicited by COVID-19 to the global ocean, environment and society may indeed present a platform for change and an opportunity to 'reset' trajectories in the coming decade (as discussed in Pecl et al. in prep). The sustainable future presented here is one option for such a shift.

\section{Alternative futures for $\mathbf{2 0 3 0}$}

The four high-impact, high-influence umbrella drivers we identified for responding to the challenge of climate-driven species redistribution in the oceans are: (1) monitoring and detection of species redistributions, (2) timely management at multiple scales, (3) cooperation between jurisdictions, and (4) human adaptation (Fig. 3). Descriptions of alternative trajectories-business as usual versus more sustainablefor these four key drivers are provided below. These descriptions form the basis of two 'narratives' of 2030 futures: one in which we are "chasing our tails and our fish" (the business as usual future) and an alternative future in which there is "dynamic adaptation to species on the move" (a technically possible and more sustainable future) (Table 2).

\section{Driver 1: Monitoring and detection}

The degree and effectiveness of monitoring and detection of range shifts (including movement of disease, toxins and pathogens) in the marine environment is a critical precursor to successful adaptation and management (Bonebrake et al. 2018; Link et al. 2011; Pecl et al. 2017). To date, monitoring and detection of species redistribution has been relatively scattered, often localised and not standardised across boundaries, making it difficult to draw comparisons across data sets and/or different spatial and temporal scales (Bates et al. 2015; Brown et al. 2016).

Under a business as usual future for this driver we envisage that there may be a shift towards more coordinated monitoring and open access to data, but this remains a challenge across jurisdictions, and among nations with different availability of resources to adequately support monitoring and subsequent data handling, storage and processing (Maureaud et al.
2020). Moreover, the rise in popularity (and value) of citizen science (e.g. Pecl et al. 2019b) and inclusion of Indigenous knowledge could result in extensive localized and non-standardised sampling, if not carefully coordinated and informed by collaborations with scientific teams. Whilst such data may be locally useful, they may or may not meet broader methodological standards. Data collection under this future could be biased towards economically important and charismatic species, and the detection of pathogens that impact human health. While monitoring conducted by wealthier nations could cover greater spatial scales (e.g. Australian monitoring might also encompass Indonesia), these data might not be available to developing countries because institutes in developed nations undertake most of the analyses (e.g. Barber et al. 2014). While we foresee that the quantities of monitoring data will increase, these data may not necessarily be as relevant as they could potentially be for decision-making because they may not be available in a form that can easily inform adaptation to species redistribution.

A more sustainable and technologically possible future for monitoring and detection of species redistribution could involve globally-coordinated networks of standardised monitoring, using advances in technology and citizen science (Edgar et al. 2020; Gervais et al. in review; Newman et al. 2012; Newman et al. 2019; Pecl et al. 2019b; Stuart-Smith et al. 2017). This will depend on addressing challenges around sharing of monitoring data among jurisdictions (see Driver 3 below). In this alternative future there will be sufficient funds and attention for culturally appropriate interdisciplinary collaboration (IT, social sciences, philosophy, statistics, biology, and Indigenous and traditional communities as full partners operating under Free Prior Informed Consent) to develop approaches that can make use of standard scientific data, citizen science, as well local and Indigenous data and knowledge streams. Examples of such collaboration are happening already, including the Haida Nation, the Maori, and to a certain extent in the Arctic in the Bering Sea (Mustonen and Van Dam in press), Alaska, Western Greenland (Johnson et al. 2015) and the Sámi areas of the European North (Mustonen et al. 2018). One method of framing ecosystem change due to species redistribution in a meaningful way across Indigenous nations would be the development of some form of 'Event Database' of marine change-both for 
Table 2 Narratives of alternative 2030 futures

Evidence to support these narratives is provided in the main text as part of descriptions for drivers $1-4)$. Left hand panel republished with permission from Scheffers and Pecl 2019, credit for both cartoons is Bas Köhler, www.baskohler.nl .
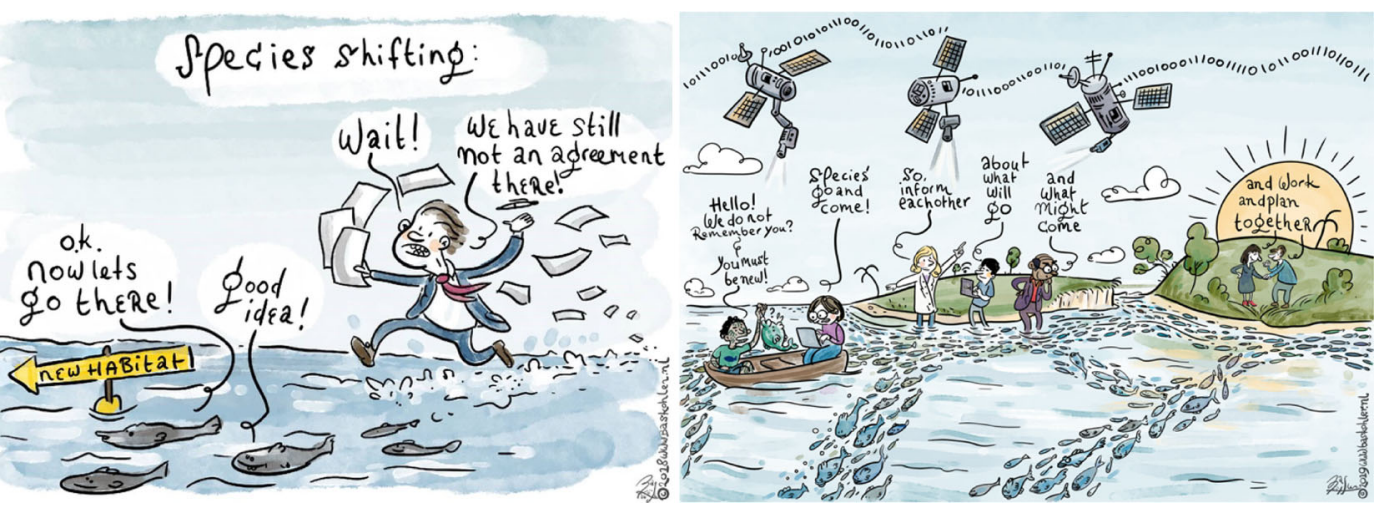

\section{Chasing our tails and our fish (Business as usual)}

- Passive and reactive

- Unconnected information transfer

- Nationalistic/individualistic

- Growth economy

- Short-term planning

- Focus on sovereignty and access

- Lags between detection and response

Much of society remains 'on the back foot' reacting to shifts in the distributions of species and associated resources. Managers and industry continue to plan mostly in the short term and to rely economically on shifting species in the absence of new regulatory frameworks. Scientists are reactive, seeking to deliver to proximate needs of stakeholders, rather than providing long-term guidance. Individuals, corporations and nations continue to predominantly act selfishly and competitively to maximize opportunities to exploit species that are moving out and to gain first access to new resources as they move in. Among nations, this translates to focus on strengthening sovereignty and exclusive access to marine resources both within and beyond national jurisdictions and increasing economic nationalism and protectionism. Economic growth and increasing wealth continue to be the primary goals of most actors. Monitoring and sampling are focused on economically important and charismatic species, with little effort in international waters and in the jurisdictions of poorer countries. Cooperation, information and knowledge sharing are generally haphazard, largely driven by isolated and underfunded initiatives. As a consequence, there are lags between detection of changes and decision-making. Society remains distrustful of science and managers, and public awareness of the state of marine ecosystems is low and biased by selective reports in traditional and social media.
Dynamic adaptation to species on the move (More sustainable)

- Adaptive and proactive

- High information transfer (networked)

- Collaborative and cooperative (coordinated)

- Circular and shared economy (stewardship)

- Long-term planning

- Shared resources

- Real-time monitoring and adaptive management

Society co-operates in the study, sustainable use and protection of marine ecosystems, ensuring equitable benefits across society groups, nations and generations. Indigenous rights regarding the sea have been supported and ratified. Proactive co-operative and coordinated adaptation are guided and informed by wellcommunicated, openly-shared and real-time knowledge, enabled through the involvement of modern technologies and citizen participation, including genuine and mutually beneficial collaborations with Indigenous communities. There is a robust and dynamic link between science and policy with strong investment in monitoring and observing systems, including the capacity required to turn observations into knowledge for informed decision-making. Management, science, and data collection systems are adaptive and dynamically interlinked through clearly established and well-communicated frameworks, including feedbacks between components. These feedbacks and strong investment in effective science communication ensure that society and nations are informed and engaged in decisionmaking, allowing for more effective implementation of dynamic policies within and between countries. Marine ecosystem users and managers recognise that changes are inevitable and work cooperatively to anticipate and prepare for them to maximise overall benefits and sustainability. Nations actively share data and expertise, to embrace a collective international response to marine ecosystem management and restoration. Societies and economies transition towards full accounting for externalities; moving species are not unsustainably exploited but are seen and managed in the context of ecosystem change and ecosystem services, such as biodiversity maintenance of biodiversity or carbon sequestration. 
the past, present and future (note, the Indigenous concept of time is divergent from linear time). This database would service the needs of the communities and science, and would not necessarily need to be electronic but could also be physical (museums, stories/narratives or perhaps 'housed' in families or institutions) so that logistically it is also equitably accessible. For example, the collection of fish species information by small scale fishers in developing nations (with support from non-governmental organisations) helps builds capacity and ecological knowledge for local communities (e.g. Almany et al. 2010) especially if analysed by local institutes. With adequate support, investment and technology, monitoring could be longer-term and cover a wider geographic area as well as greater depths of the oceans. Monitoring and detection data summarised into useable formats, such as regular report cards, together with enhanced communication of findings to government, industry and the public would better assist decisionmaking and adaptation.

\section{Driver 2: Managing at multiple scales}

The temporal and spatial scale of ocean management will also play a key role in addressing the challenge of species redistribution. Current management responses to species redistributions suffer from several problems: (1) lag between detection of distributional change and management response (Maxwell et al. 2015), (2) often rigid management frameworks that, for example, are set for specific areas rather than acknowledging that species move in space, and (3) static marine protected areas (both in space and in terms of objectives) that cannot adapt to shifting ranges (D’Aloia et al. 2019; Meyer-Gutbrod et al. 2018b).

By 2030 under a business as usual approach we suggest that-based on current practise and trajectories-management will remain reactive, with a mismatch between the scale of ecological change and management decisions taken, and only limited examples of smaller-scale responsive management. The existence of lags between detection of change and a management response will also mean that by the time actions occur, the situation will have changed again (i.e. species may have moved even further than at previous detection) and therefore management may be ineffective.
By contrast, under a more sustainable scenario, by 2030 we could see broader adoption of extensive, proactive dynamic ocean management approaches (Table 3) at a variety of appropriate spatial scalesessentially spatial scales which are relevant to stock distribution, productivity changes and sustainability (Gaines et al. 2018; Hobday et al. 2014; Maxwell et al. 2015). This alternative future would include approaches as simple as vessel communication regarding bycatch (Maxwell et al. 2015; O'Keefe and DeCelles 2013) or near-real time area closures, to the use of seasonal to decadal-scale forecasts and predictions to inform actions and risk management where capacity exists (e.g. see Payne et al. 2019; Tommasi et al. 2017). These approaches would be coupled with ecosystem-based fisheries management and operationalised integrated management (Fulton et al. 2019; Stephenson et al. 2019), and could include managed relocation of key species (Schwartz et al. 2012).

\section{Driver 3: Cooperation between jurisdictions}

The degree of cooperation, coordination and communication between jurisdictions at local, regional and international levels will be an important factor in influencing future outcomes related to the challenge of species redistribution in the ocean (and as articulated by Pinsky et al. 2018; Scheffers and Pecl 2019). While there is currently some localised cooperation between jurisdictions, either for particular fisheries or between particular countries, and a few international agreements for transboundary stocks or threatened, endangered or protected species (TEPs) exist, there is often no coordination in the management of different (potentially moving) stocks. Individual jurisdictions may be protective of 'their' stocks and hesitant to share information with adjoining regions (e.g. Spijkers and Boonstra 2017).

For a business as usual 2030, we envisage potential increases in nationalism as resources become limited and/or climate refugees increase, resulting in no substantial increase (and possible decreases) in international cooperation. International conflicts may also increase due to changes in shared stocks. In this scenario shared stocks are often not managed well because without shared data the stock is not assessed accurately and/or because regulations differ across jurisdictions leading to overfishing and eventual stock 
Table 3 What is dynamic ocean management?

Most spatial marine management techniques (e.g. marine protected areas) draw stationary boundaries around often mobile marine features, animals, or resource users. While these approaches can work for relatively stationary marine resources in a world without climate change, Maxwell et al. (2015) argue that to be effective, marine management must be as fluid in space and time as the resources and users that we seek to manage. In a fast-changing ocean, fast-changing management instruments must be considered.

Dynamic ocean management (DOM) is defined as management that changes in space and time in response to changes in the ocean and its users through the integration of near real-time biological, oceanographic, social and economic data (Maxwell et al. 2015; Fig B1). A range of species-based examples of DOM have been described by Lewison et al. (2015) spanning whales to tuna to salmon.

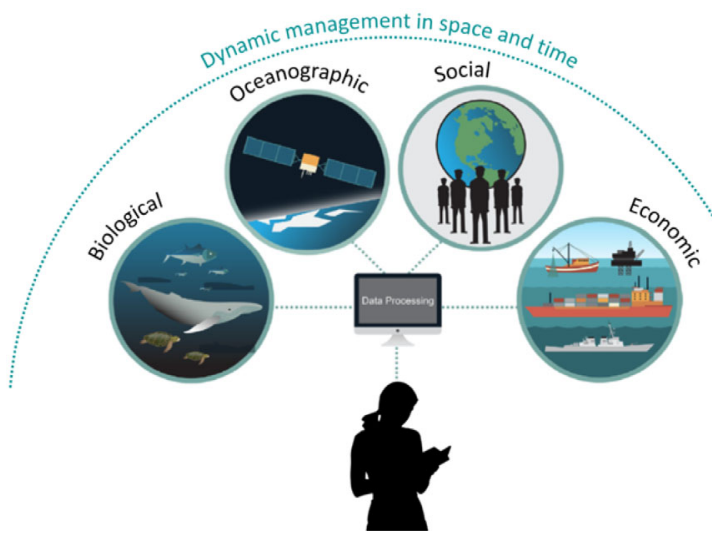

Dynamic ocean management integrates near realtime biological, oceanographic, social and economic data such that management in space and time is responsive to biophysical and socioeconomic change (modified from Maxwell et al. 2015).

An advantage of DOM over static area-based management is that continually updating the temporal and spatial scale of managed areas can help to balance ecological and economic objectives. For example, Maxwell et al (2015) showed that for a hypothetical mobile marine species between $82-34 \%$ less total area would need to be protected using a dynamic approach (potentially improving efficiency and efficacy of protection and reducing socioeconomic trade-offs). Although we advocate a sustainable future that increases dynamic spatial management, that does not mean that static MPAs should decrease, as they provide important baseline conditions relevant to monitoring (Monitoring and Detection driver) and protection of habitats or populations that have little to no ability to shift.

A second advantage of DOM is an increase in the speed at which decisions are implemented using predefined protocols. Advances in data collection and sharing, particularly in remote sensing, animal tracking, and mobile technology support delivery of DOM in limited regions around the world (e.g. Hobday and Hartmann 2006; Hobday et al. 2011). Dynamic fisheries management has also been shown to increase the efficiency and revenue of marine fisheries (Dunn et al. 2016; O'Keefe and DeCelles 2013).

To improve the efficacy of DOM will require enhancing legal instruments (Hobday et al. 2014), incorporating ecological and socioeconomic considerations, and developing platforms to serve dynamic management data to users (e.g. EcoCast; Hazen et al. 2018). The examples of DOM to date have been species-focused, rather than ecosystem or community focused. Developing examples of how to apply DOM to eco-regions that might shift through space and time will bring advantages over a single species approach.

To better address the challenge of climate-driven species redistribution, DOM could be used proactively, such that species shifts are anticipated and planned for before they occur, and those plans are then implemented through DOM (and other means) as the shifts occur. This will also likely require an agreed language with which to describe, manage and respond to the different stages of range shifts (as per Bates et al. 2014). 
collapse (Spijkers and Boonstra 2017). With limited information sharing there are repeated and isolated instances of trial and error responses to range shifts, which leads to lags in response times and greater risk of missing windows of opportunity for mitigating collapse or preventing the establishment of problematic climate-driven invasive species (Scheffers and Pecl 2019). Another historical divergence related to deficient cooperation has been the lack of understanding and dialogue between Indigenous and traditional knowledge and natural sciences regarding the oceans.

A more sustainable trajectory for this driver by 2030 would involve widespread cooperation and coordination between regions and countries (Scheffers and Pecl 2019). Under this scenario, assessment and management decisions lead to sustainability at the stock/species (or ecosystem) level regardless of where that stock/species is located or where it moves to. This will require a greater number of transboundary agreements and institutions (Gaines et al. 2018), reform of current agreements (Oremus et al. 2020; Pinsky et al. 2018) and better information sharing (Pendleton et al. 2019), to ensure that moving resources are sustainably managed. In this future there is a clear recognition that changing species distributions result in both winners and losers, and that cooperation requires countries and international agreements to have mechanisms to compensate (e.g. side payments) "those who loose" (or those who bear the burden of most of the costs of implementation) (Miller et al. 2013). Indigenous people are not just seen as stakeholders but are more broadly recognised as rights holders. Indigenous and traditional knowledge is more widely accepted and acknowledged by western scientists, and genuine collaboration between knowledge systems substantially increases capacity to understand changes in species distributions, implications of these changes, and potential adaptation options.

\section{Driver 4: Human adaptation}

Finally, human adaptation-both social and economic-will play an important role in the ability of human communities to respond to climate-driven species redistribution, including their ability to benefit from new opportunities that arise from species shifts (Ottersen and Melbourne-Thomas 2019; Pecl et al. 2019a; Pershing et al. 2019). Research indicates that a "backward looking" strategy to adaptation performs more poorly than "forward looking" adaptation (Pershing et al. 2019). Currently, there are only isolated examples of adaptation planned and undertaken at regional or national levels (Miller et al. 2018; Pecl et al. 2019a), often with more theoretical examples than action plans. Overall, nations, regions or regional fisheries management organisations rarely actively plan for species redistributions (Pershing et al. 2018; Sumby et al. 2021). Moreover, adaptation planning is mainly incremental and in step with (or even lagging behind) actual changes, rather than being pre-emptive or transformational (Ogier et al. 2020; Pinsky and Mantua 2014). Ambiguity around ecosystem or fisheries values can lead to opaque adaptation decision processes (Jennings et al. 2016).

Under a business as usual 2030 there will continue to be slow and incremental advances in human adaptation at local, regional and global scales, mainly by trial and error, and reacting to species shifts as they occur rather than preparing for them. This scenario would likely involve continued economic reliance on species that are moving as opposed to looking forward and working to shift such dependencies dynamically.

The proactive, sustainable future for this driver would hinge on proactive adaptation, guided and informed by well-communicated, real-time or projected/predicted knowledge (linked to the monitoring and detection driver described above). Adaptation would be coordinated across scales, with links between local communities and industry for sharing social and economic indicators of change alongside ecological variables. Enhanced information sharing and awareness would build public trust in science and management, and empower the public to make more informed and adaptive choices (Pecl et al. 2019a).

\section{Pathway for achieving a more sustainable future}

We identified a set of 20 actions, each associated with one of our umbrella drivers, that together could constitute a pathway for achieving a more sustainable future under climate-driven species redistribution (Fig. 4). Because of the number of actions associated with the human adaptation driver (12 of the total 20 actions; Fig. 4), we classed these by whether they were related to (1) adaptive management, engagement communication and knowledge co-production, or (2) 


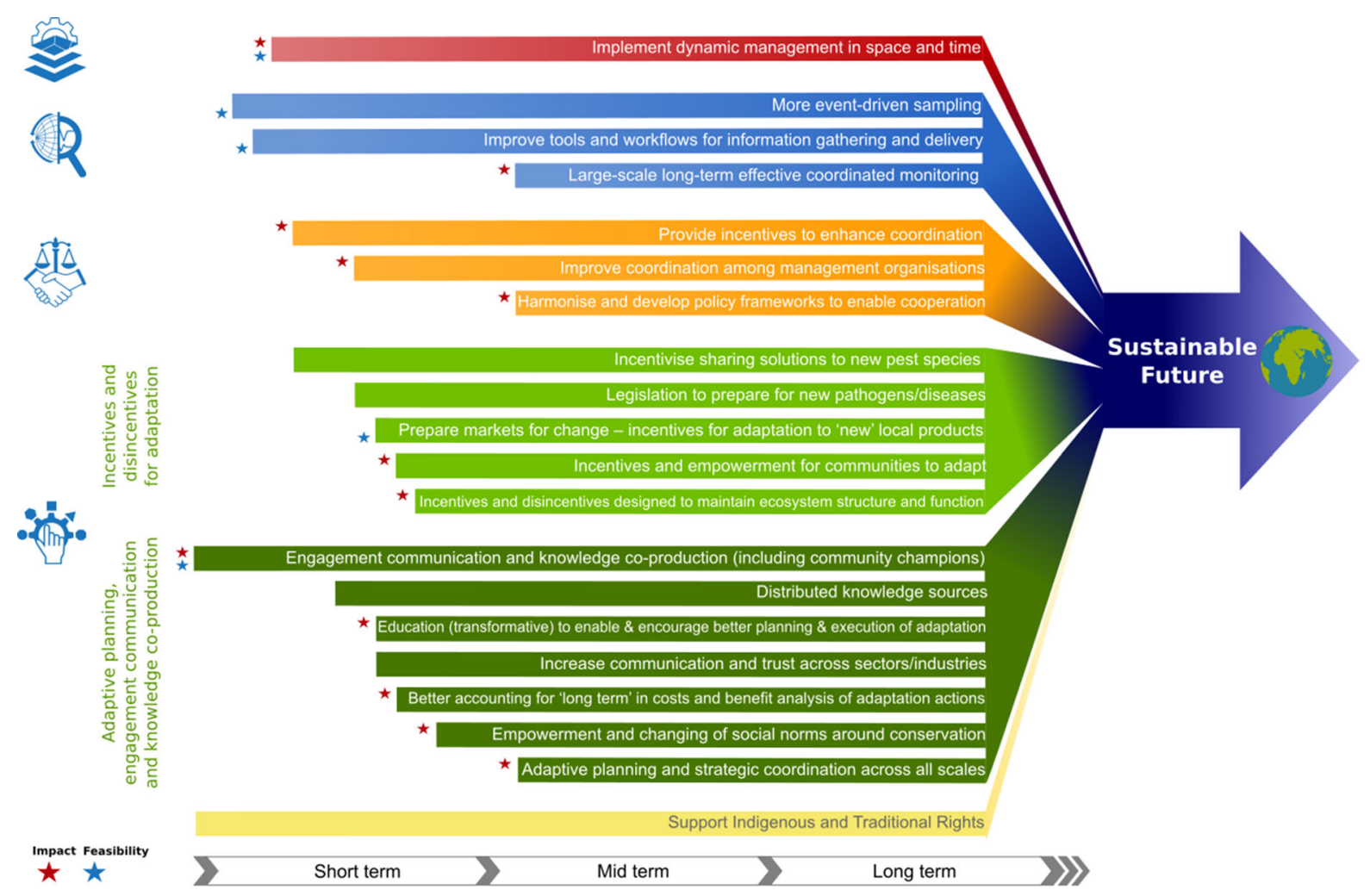

Fig. 4 Actions and timeframes for achieving a more sustainable future regarding climate-driven species redistribution in the ocean. Short term is 2021-2025, medium term is 2025-2030 and long term is beyond 2030. The starting point of each arrow indicates the time period in which each action might usefully be initiated. Red stars indicate actions that we considered to have high impact on achieving a desirable future outcome, and blue stars indicate actions that are considered to have high feasibility

incentives and disincentives for adaptation. For each action we also considered which timescales (short, medium or long-term) they would most usefully take place over, where short-term is (approximately) 2021-2025, medium-term is 2025-2030 and longterm is beyond 2030. An assessment of the feasibility and impact of each action in terms of achieving the sustainable future is also indicated in Fig. 4, and Table 4 provides a summary of tactical and strategic goals across these timescales. Table $\mathrm{S} 2$ provides a list of risks and benefits for groups of actions.

Actions associated with monitoring and detection

The actions related to our monitoring and detection driver are: more event-driven sampling, improved tools and workflows for information gathering and delivery, and large-scale long-term effective coordinated monitoring. Engagement of local and Indigenous groups to help collect data on species range shifts, including via citizen science, will be an important element in monitoring and detection. Where possible, smartphone apps for upload and download of data, combined with automated data flows, standardised collection frameworks (e.g. fisher apps all collect effort, size, location, species data), and the application of artificial intelligence for rapid processing will enhance the utility of such data. However, in cases where resources and capacity are more limited (such as in developing countries), locally appropriate technology can also be used effectively. Frainer et al. (2020) describe how many Indigenous and Community-Conserved Area's (ICCA) undertake monitoring and detection without electronic devices and internet (for example the Kawawana in Mangagoulack Rural Community, Senegal), with benefits for communities 
Table 4 Short-, medium- and long-term goals in achieving a more sustainable future under climate-driven species redistribution

\section{SHORT-TERM TACTICAL GOALS}

New frameworks for data collection and processing developed and implemented

Common language about status of range shifts adopted (Bates et al. 2014)

Tools and statistical methods to facilitate the use of citizen science data in a consistent manner

Effective and dynamic management of change across scales through dynamic ocean management demonstrated (see Table 3)

Existing legal frameworks revised to improve coordination and cooperation within nation states (at the sub-national level) and within existing regional bodies

International database of 'best-practice' domestic legal arrangements and case studies developed and can be adapted and promoted for legal and policy reform elsewhere

Increased communication and collaboration, as well as enhanced anticipation and knowledge sharing with respect to range shifts

Government support to enable industry to respond and adapt, including transitional support for companies that are implementing sustainable practises

Industry standards established to set appropriate baseline responses to species redistribution, including reporting and information feedbacks

Enhanced reinvestment in protecting ecosystem function (e.g. Table 5)

\section{MEDIUM- TO LONG-TERM STRATEGIC GOALS}

Broad-scale availability and deployment of automated detection technologies

Incentives for citizen science available

Strategic, useable, aligned and adaptive approaches for monitoring and detection with iterative development and updating

Integrated 'toolbox' approaches for monitoring and detection including management feedbacks

Agility for responding to emerging challenges (e.g. pathogens, tipping points)

Scalable management structures/strategies

Increased adaptive capacity (with more win-win), and management that maintains and builds resilience of natural systems

Wide recognition of the value of dynamic ocean management, with system benefits clear and well acknowledged

Effective institutional learning and knowledge-sharing (from successes and failures) for dynamic ocean management

Pre-emptive agreements for management of species redistribution

Successes at national and regional scales used to help develop and implement new international rules and processes

Obligations on nation states and sub-national marine management bodies to cooperate across

borders in managing shifting marine species

Indigenous access and rights are supported at all scales 
Table 4 continued

Icons indicate the drivers that each goal relates to $(\mathcal{Q}$ monitoring and detection, $\cong$ scale of management, cooperation between jurisdictions, $\underset{\text { - }}{ }$ adaptation)

and for conservation and management. The development of tools to integrate various science platforms will also be a key part of the coordination element of monitoring and detection. Concerted and well-funded effort to combine different sources of data-given their biases, uncertainties, limitations and strengthswill help ensure that the best available data streams are used for decision-making and that there is an accepted framework to estimate uncertainties with alternative decisions given the available knowledge (Addison et al. 2017). Such tools could better enable the comparison of new observations with baseline data (e.g. Stuart-Smith et al. 2017). Increased real time monitoring will likely increase the demand and requirement for experts to turn data into knowledge and update predictive models to inform understanding of potential futures.

In the future it is likely that legal agreements for monitoring, gear deployment and recovery will be increasingly important as species shift across national boundaries (Hobday et al. 2014). Allowing such agreements for data collection to be "platform free" will help avoid the need for re-negotiation as new technologies emerge, for example moving from sampling organisms to collecting eDNA. Retaining Indigenous control and ownership of local data will also be important as species move in the future (Table 1). Event-driven sampling in response to unusual or extreme conditions (e.g. marine heatwaves) could help identify the effects of such events on species redistribution, and could usefully be linked to pre-defined stages of range expansion and contraction (Bates et al. 2014).

Effective and coordinated large-scale, long-term monitoring will require actions by researchers, data contributors, end-users of data streams as well as other interest groups (such as tech companies). This requires the staged and supported rollout of tools that are fit and scaled for purpose, and could usefully include semi- or fully-automated report-cards, the design of data acquisition and reporting tools that are appealing and easy to use, as well as the development of methods that integrate non-traditional data collection approaches into fisheries management and conservation. The potential effects of economic disruption related to the 2020-2021 COVID-19 pandemic on investment in monitoring and detection in the next 10 years are unclear, but may in fact provide a pivot point for change in future climate-change related investment priorities.

Actions associated with managing at multiple scales

The key action related to our scale of management driver is the implementation of dynamic ocean management in space and time-including temporal closures - and at both small and large scales (Table 3). In many ways, achieving effective dynamic ocean management requires a complete paradigm shift, hence we provide some examples of the types of actions that can be taken to achieve this. At the local scale these could include activities by Indigenous and local community groups (Indigenous and Community Conserved Areas), by individual companies (e.g. the use of real time feedback to fallow leases in aquaculture), co-management structures (e.g. Table 5) and informal agreements to leave areas closed or open (subject to consideration of risks such as disease or overfishing). At larger scales, dynamic ocean management can be implemented by national resources management agencies (within their Exclusive Economic Zones) and by Regional Fisheries Management Organisations in areas beyond national jurisdiction. Importantly, dynamic ocean management requires adequate availability of information and delivery of that information (and so there are strong links to actions related to monitoring and detection), as well as stewardship and evidence of compliance.

Actions associated with cooperation between jurisdictions

Improving cooperation between jurisdictions will require three key, overarching reforms to legal and policy frameworks: (1) implementing new 
Table 5 Case study on the use of abalone royalties to control range shifting urchins (Tasmania, Australia)

\section{Driver: Monitoring and detection}

The south-eastern coast of Australia has been identified as a climate change hotspot due to strengthening and poleward advance of the warm East Australia Current (Hobday and Pecl 2014). This has led to range extension of Centrostephanus rodgersii (Longspined) sea urchin, a powerful grazer responsible for the formation of urchin barrens along its entire range. Since their first discovery in Tasmania in 1978, Longspined urchin populations have increased to an estimated 20 million individuals by 2017 with associated increase in barrens cover increasing to $\sim 15 \%$ of rocky reefs (Ling and Keane 2018). The destruction of kelp forests in Tasmania has a negative impact on the many species that rely on healthy kelp forests, including abalone, rock lobster and fish, as well as recreational and commercial fisheries that harvest these species. Financially, the greatest impact is to the rock lobster and abalone fisheries (Cresswell et al. 2019).

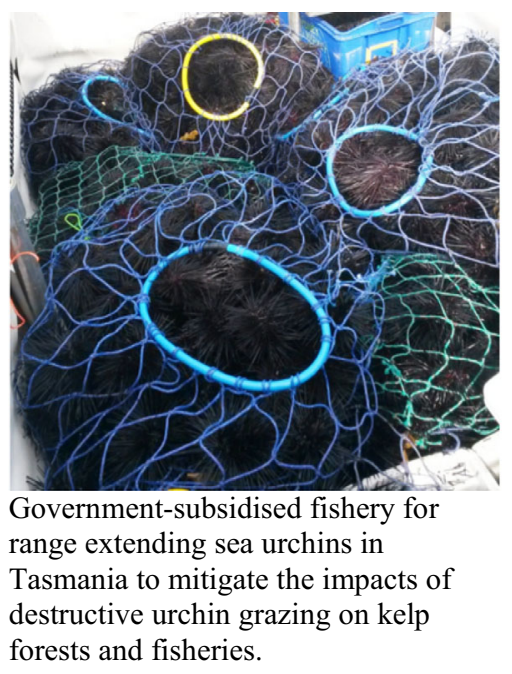

Driver: Co-operation between jurisdictions - abalone industry, government, urchin harvesting industry, harvesters and researchers

Action - Provide incentives to enhance coordination

Action - Increase communication and trust across sectors/industries

Commercial harvesting of Longspined sea urchins in Tasmanian began in 2009. After a slow start to the fishery followed by a sudden decline in catch in 2015, the Tasmanian Abalone Council began subsidising the urchin fishery in 2016 in an effort to control increasing sea urchin numbers and associated destructive grazing of kelp forests, productive abalone habitat (Cresswell et al. 2019). In 2019, a committee of researchers, government, harvesters, and industry representatives, the Abalone Industry Reinvestment Fund (AIRF), took over administration of the subsidy. The AIRF contains funds of $\$ 5.1$ million which comprised $2 \%$ (out of total $7 \%$ ) of the royalties that the abalone industry pays to the government. The funds are to be spent on the subsidy as well as research into preventing further spread of barrens and to promote recovery of extensive barrens, with an aim to increase the sustainability and productivity of the Tasmanian abalone fishery. Since the subsidy began, the urchin catch has increased dramatically, resulting in removal of 560 tonnes (1.5 million urchins) in 2019 alone. The motivation of the abalone industry to subsidise the urchin fishery although not altruistic does align with supporting kelp forest recovery by controlling a range-extending destructive species.

\section{Driver: dynamic ocean management}

\section{Action - implement dynamic management}

Changes to the spatial structure of the subsidy were made before and after the 2019/20 harvest season to incentivise divers to spread harvesting along the coast (to effectively remove urchins on a greater spatial range of reefs).

'facilitative' arrangements for cooperation; (2) improving innovation and coordination across sectors and governance scales within nation states; and (3) improving communication and cooperation between nation states. These reforms will depend on the active involvement of multiple diverse actors such as government and marine management agencies; fishing, 
aquaculture and tourism industries; researchers; conservation groups; and local communities.

First, improving coordination will require new 'facilitative arrangements' such as incentives for integrated management, the transfer of resource rights, and integrating a clear definition of what constitutes 'best available science' into legal frameworks at all scales. Such arrangements can help to clarify obligations on decision-makers to take a more futurefocused approach and enhance the adaptiveness of decision-making to changing species distributions.

The second requirement for improving cooperation is to ensure engagement between the multiple diverse sectors and communities that will be affected by shifting species ranges, such as fishing and energy industries, Indigenous communities and corporations, tourism, conservation and recreational users across governance scales (see Fischer et al. 2020; Haas et al. 2020; Smith et al. 2020).

The third requirement for improving cooperation between jurisdictions requires nation states to improve communication and cooperation with each other, as species shift across international borders. A crucial starting point will be to elicit agreement on overarching high level principles and objectives to guide decision-making at different scales. This may include re-asserting the principles of the United Nations Fish Stocks Agreement 1995 and ensuring that national laws and regulations are consistent with them (see Haas et al. 2020; Smith et al. 2020).

Regional organisations and states within regional blocs should review existing agreements and measures, and consider negotiating (or re-negotiating) new agreements where similar interests or overlapping fisheries support cooperation. Successful examples of networks of marine protected areas or fisheries management that consider ocean connectivity (e.g. McLeod et al. 2009; Rassweiler et al. 2020; see also Table 3) provide lessons for developing incentives, priorities and obligations to enhance cross-jurisdictional marine connectivity.

Actions associated with human adaptation

Like many climate change challenges, adaptation to shifting species and fisheries will require engagement and responses across all aspects of society. The visibility of species on the move has tremendous potential to connect people with the reality of climate change through their 'lived experience', for example recreational fishers and divers observing species shifts in coastal environments (e.g. Pecl et al. 2019b). Scientists and institutions can adapt by adopting emerging approaches such as knowledge co-production (Norström et al. 2020) and research funding bodies could become more flexible to support nontraditional applications, applied science, and projects that involve international researchers. At the societal and decision-making levels, enhanced appetite for risk and flexibility to learn from "mistakes" as part of adaptive management will likely be needed (Catalano et al. 2019), with longer-term decision-making decoupled from shorter-term election cycles. Education programs could also better support critical and adaptive thinking. Regulatory frameworks (and social license) for private industry, such as a requirement for making data publicly available (including requirements for monitoring) could further support adaptation in the context of marine species redistribution. This could also include engagement of researchers with private sector/insurance industry on understanding risk and industry requirements to report observations of new pathogens and parasites. Finally, a system in which some form of bond was paid for risky activities would enable such funds to be used for mitigation and restoration. For example, decommissioned sites (such as offshore oil and gas infrastructure) could be used to experiment with new habitat for species redistribution.

Further considerations and challenges

Our treatment of the issue of climate-driven marine species redistribution, and in particular our consideration of what might be done in the 2021-2030 timeframe to move towards a more sustainable future in the face of this challenge, is not intended to be exhaustive. Moreover, the effects of the 2020-2021 COVID-19 pandemic mean that some of the drivers and related actions we describe are currently in a state of flux. While we do not yet have the evidence to identify how these might look once the pandemic has passed, we emphasise that there will likely be important opportunities to pivot these drivers in a more sustainable direction in the near future. Our considerations of the challenge of climate-driven species redistribution are also partly constrained by the expertise of the contributing authors and by the particular methodology we have adopted. While we 
believe that the set of actions we have outlined does provide a tangible and achievable pathway towards a more sustainable 2030, there are a series of important considerations for addressing the challenge of species redistribution that are either not captured or only partially captured in the drivers and actions described in this paper. Some particular considerations to highlight include:

1. The effect of species redistribution on cultural connections for Indigenous communities. Indigenous communities need their rights respected and recognized to ensure and facilitate their capacity to understand and get to know new species and their associated spirits within their territories (Table 1). New species and beings have to be welcomed and learned about once they arrive in the Indigenous home areas. Development of ranger programmes, community-based monitoring using cultural indicators, establishment of Event Databases of marine change and resourcing Indigenous governance of the sea are seen here as priorities. Some changes, such as the recent proliferation of Pink Salmon across the Barents and North Atlantic has caused additional burdens on Sámi fisheries (Mustonen et al. 2018) and represents an originally human induced introduction of new species to a new area that has since gone viral with potentially cascading impacts for the whole ecosystem on freshwater and at sea. This case illustrates the complexity of the realities facing Indigenous communities today.

2. Considerations related to the management of range-shifting 'invasive' species (Scheffers and Pecl 2019), including:

(i) decisions on whether to protect such species that may be at risk of becoming functionally extinct in their native range; and

(ii) investment of effort in protecting native species that have no long-term chance of surviving in changed habitat, but obligations to remove invasive species (that may end up being the only thing left, or even provide longer-term unexpected benefits).

3. Management decisions specifically related to translocation of species and/or the creating of stepping stones and refugia for conservation (D'Aloia et al. 2019).

\section{Conclusions}

Climate-driven species redistribution is already one of the most pronounced and challenging impacts of ocean warming at local and global scales. Understanding how to tackle this challenge at multiple scales, and acting strategically over the coming decade, will be important to ameliorate the negative impacts of these changes, to respond in an informed and coordinated way to opportunities that might arise from these shifts, and to move towards a more sustainable future of ocean stewardship. Here we have outlined a set of key drivers and associated, tangible actions, including knowledge exchange, adaptive management and cooperation, that together could form a pathway towards this sustainable future.

Acknowledgements This paper is part of the 'Future Seas' initiative (www.FutureSeas2030.org), hosted by the Centre for Marine Socioecology at the University of Tasmania. This initiative delivers a series of journal articles addressing key challenges for the UN International Decade of Ocean Science for Sustainable Development 2021-2030. The general concepts and methods applied in many of these papers were developed in large collaborative workshops involving more participants that listed here as co-authors here, and we are grateful for their collective input. Funding for Future Seas was provided by the Centre for Marine Socioecology, IMAS, MENZIES and the College of Arts, Law and Education, and the College of Science and Engineering at UTAS, CSIRO and Snowchange from Finland. We acknowledge support from a Research Enhancement Program grant from the DVCR Office at UTAS. Thank you to Kirsty Nash for providing an internal project review of an earlier draft, and to two anonymous reviewers whose comments served to greatly improve our paper. We acknowledge and pay respect to the Traditional Owners and custodians of sea country all around the world, and recognise their collective wisdom and knowledge of our oceans and coasts.

Funding Centre for Marine Socioecology, IMAS, MENZIES, College of Arts, Law and Education, and the College of Science and Engineering at UTAS, CSIRO and Snowchange.

Availability of data and materials Provided as supplementary material.

\section{Compliance with ethical standards}

Conflict of interest The authors declare that they have no conflict of interest. 


\section{References}

Addison PFE et al (2017) A new wave of marine evidence-based management: emerging challenges and solutions to transform monitoring, evaluating, and reporting. ICES J Mar Sci 75:941-952. https://doi.org/10.1093/icesjms/fsx216

Allison EH et al (2009) Vulnerability of national economies to the impacts of climate change on fisheries. Fish Fish 10:173-196. https://doi.org/10.1111/j.1467-2979.2008. 00310.x

Almany GR et al (2010) Research partnerships with local communities: two case studies from Papua New Guinea and Australia. Coral Reefs 29:567-576. https://doi.org/10. 1007/s00338-010-0624-3

Amara R (1984) New directions for futures research—setting the stage. Futures 16:401-404

Barber PH et al (2014) Advancing biodiversity research in developing countries: the need for changing paradigms. Bull Mar Sci 90:187-210. https://doi.org/10.5343/bms. 2012.1108

Bates AE et al (2015) Distinguishing geographical range shifts from artefacts of detectability and sampling effort. Divers Distrib 21:13-22. https://doi.org/10.1111/ddi.12263

Bates AE et al (2014) Defining and observing stages of climatemediated range shifts in marine systems. Glob Environ Change 26:27-38. https://doi.org/10.1016/j.gloenvcha. 2014.03.009

Belhabib D, Dridi R, Padilla A, Ang M, Le Billon P (2018) Impacts of anthropogenic and natural "extreme events" on global fisheries. Fish Fish 19:1092-1109. https://doi.org/ 10.1111/faf.12314

Belhabib D, Lam VWY, Cheung WWL (2016) Overview of West African fisheries under climate change: Impacts, vulnerabilities and adaptive responses of the artisanal and industrial sectors. Mar Policy 71:15-28. https://doi.org/10. 1016/j.marpol.2016.05.009

Bonebrake TC et al (2018) Managing consequences of climatedriven species redistribution requires integration of ecology, conservation and social science. Biol Rev 93:284-305. https://doi.org/10.1111/brv.12344

Börjeson L, Höjer M, Dreborg K-H, Ekvall T, Finnveden G (2006) Scenario types and techniques: towards a user's guide. Futures 38:723-739. https://doi.org/10.1016/j. futures.2005.12.002

Boschetti F et al (2020) Sectoral futures are conditional on choices of global and national scenarios-Australian marine examples. Front Mar Sci 7:935

Brown CJ et al (2016) Ecological and methodological drivers of species' distribution and phenology responses to climate change. Glob Change Biol 22:1548-1560. https://doi.org/ 10.1111/gcb.13184

Catalano AS, Lyons-White J, Mills MM, Knight AT (2019) Learning from published project failures in conservation. Biol Conserv 238:108223. https://doi.org/10.1016/j. biocon.2019.108223

Cheung WWL, Lam VWY, Sarmiento JL, Kearney K, Watson R, Pauly D (2009) Projecting global marine biodiversity impacts under climate change scenarios. Fish Fish 10:235-251. https://doi.org/10.1111/j.1467-2979.2008. 00315.x
Cheung WWL, Lam VWY, Sarmiento JL, Kearney K, Watson REG, Zeller D, Pauly D (2010) Large-scale redistribution of maximum fisheries catch potential in the global ocean under climate change. Glob Change Biol 16:24-35. https:// doi.org/10.1111/j.1365-2486.2009.01995.x

Cheung WWL, Lam VWY, Sarmiento JL, Kearney K, Watson R, Zeller D, Pauly D (2010) Large-scale redistribution of maximum fisheries catch potential in the global ocean under climate change. Glob Change Biol 16:24-35. https:// doi.org/10.1111/j.1365-2486.2009.01995.x

Clavero M (2014) Shifting baselines and the conservation of non-native species. Conserv Biol 28:1434-1436. https:// doi.org/10.1111/cobi.12266

Cresswell KA, Keane JP, Ogier E, Yamazaki S (2019) Centrostephanus subsidy program: initial evaluation. Institute for Marine and Antarctic Studies, University of Tasmania, Hobart

D'Aloia C et al (2019) Coupled networks of permanent protected areas and dynamic conservation areas for biodiversity conservation under climate change. Front Ecol Evol $7: 27$

Dulvy NK, Rogers SI, Jennings S, Stelzenmüller V, Dye SR, Skjoldal HR (2008) Climate change and deepening of the North Sea fish assemblage: a biotic indicator of warming seas. J Appl Ecol 45:1029-1039. https://doi.org/10.1111/j. 1365-2664.2008.01488.x

Dunn DC, Maxwell SM, Boustany AM, Halpin PN (2016) Dynamic ocean management increases the efficiency and efficacy of fisheries management. Proc Natl Acad Sci U S A 113:668-673. https://doi.org/10.1073/pnas.1513626113

Edgar GJ et al (2020) Reef life survey: establishing the ecological basis for conservation of shallow marine life. Biol Conserv 252:108855. https://doi.org/10.1016/j.biocon. 2020.108855

ELOKA (2019) Oral Histories from the Lower Kolyma, SakhaYakutia, Siberia. https://eloka-arctic.org/communities/ russia/index.html. Accessed 15 Dec 2020

Fischer M et al (2020) Empowering her guardians to nurture our oceans future. Authorea. https://doi.org/10.22541/au. $160391058.89181791 / \mathrm{v} 1$

Frainer A et al (2020) Opinion: cultural and linguistic diversities are underappreciated pillars of biodiversity. Proc Natl Acad Sci 117:26539-26543. https://doi.org/10.1073/pnas. 2019469117

Frainer A, Primicerio R, Kortsch S, Aune M, Dolgov AV, Fossheim M, Aschan MM (2017) Climate-driven changes in functional biogeography of Arctic marine fish communities. Proc Natl Acad Sci USA 114:12202. https://doi.org/ 10.1073/pnas.1706080114

Francis TB, Levin PS, Harvey CJ (2011) The perils and promise of futures analysis in marine ecosystem-based management. Mar Policy 35:675-681. https://doi.org/10.1016/j. marpol.2011.02.008

Fulton EA, Punt AE, Dichmont CM, Harvey CJ, Gorton R (2019) Ecosystems say good management pays off. Fish Fish 20:66-96. https://doi.org/10.1111/faf.12324

Gaines SD et al (2018) Improved fisheries management could offset many negative effects of climate change. Sci Adv 4:eaao 1378

Gervais CR, Champion C, Pecl GT (in review) Species on the move around the Australian coastline: a continental scale 
review of climate-driven species redistribution in marine systems. Glob Change Biol

Haas B et al (2020) The future of ocean governance. Authorea. https://doi.org/10.22541/au.160193487.70124607/v1

Hazen EL et al (2018) A dynamic ocean management tool to reduce bycatch and support sustainable fisheries. Sci Adv 4:aar3001. https://doi.org/10.1126/sciadv.aar3001

Hobday A, Hartmann K (2006) Near real-time spatial management based on habitat predictions for a longline bycatch species. Fish Manag Ecol 13:365-380

Hobday AJ (2011) Sliding baselines and shuffling species: implications of climate change for marine conservation. Mar Ecol 32:392-403. https://doi.org/10.1111/j.14390485.2011.00459.x

Hobday AJ, Hartog JR, Spillman CM, Alves O, Hilborn R (2011) Seasonal forecasting of tuna habitat for dynamic spatial management. Can J Fish Aquat Sci 68:898-911. https://doi.org/10.1139/f2011-031

Hobday AJ et al (2014) Dynamic ocean management: integrating scientific and technological capacity with law, policy and management. Stanf Environ Law J 33:125-165

Hobday AJ, Pecl GT (2014) Identification of global marine hotspots: sentinels for change and vanguards for adaptation action. Rev Fish Biol Fish 24:415-425. https://doi.org/10. 1007/s11160-013-9326-6

Jennings S, Pascoe S, Hall-Aspland S, Le Bouhellec B, NormanLopez A, Sullivan A, Pecl G (2016) Setting objectives for evaluating management adaptation actions to address climate change impacts in south-eastern Australian fisheries. Fish Oceanogr 25:29-44. https://doi.org/10.1111/fog. 12137

Johnson N et al (2015) The contributions of community-based monitoring and traditional knowledge to Arctic observing networks: reflections on the state of the field. Arctic 68:28-40

Lenoir J, Bertrand R, Comte L, Bourgeaud L, Hattab T, Murienne J, Grenouillet G (2019) Species better track the shifting isotherms in the oceans than on lands. bioRxiv. https://doi.org/10.1101/765776

Lewison R et al (2015) Dynamic Ocean Management: identifying the critical ingredients of dynamic approaches to ocean resource management. Bioscience 65:486-498. https://doi.org/10.1093/biosci/biv018

Ling SD (2008) Range expansion of a habitat-modifying species leads to loss of taxonomic diversity: a new and impoverished reef state. Oecologia 156:883-894. https://doi.org/ 10.1007/s00442-008-1043-9

Ling SD, Keane JP (2018) Resurvey of the longspined sea urchin (Centrostephanus rodgersii) and associated barren reef in Tasmania. Institute for Marine and Antarctic Studies Report. University of Tasmania, Hobart

Link JS, Nye JA, Hare JA (2011) Guidelines for incorporating fish distribution shifts into a fisheries management context. Fish Fish 12:461-469. https://doi.org/10.1111/j.14672979.2010.00398.x

Lotze HK et al (2019) Global ensemble projections reveal trophic amplification of ocean biomass declines with climate change. Proc Natl Acad Sci U S A 116:12907-12912. https://doi.org/10.1073/pnas.1900194116

Maureaud A et al (2020) Are we ready to track climate-driven shifts in marine species across international boundaries? A global survey of scientific bottom trawl data. Glob Change Biol. https://doi.org/10.1111/gcb.15404

Maxwell SM et al (2015) Dynamic ocean management: defining and conceptualizing real-time management of the ocean. Mar Policy 58:42-50. https://doi.org/10.1016/j.marpol. 2015.03.014

McLeod E, Salm R, Green A, Almany J (2009) Designing marine protected area networks to address the impacts of climate change. Front Ecol Environ 7:362-370. https://doi. org/10.1890/070211

Melbourne-Thomas J (2020) Climate shifts for krill predators. Nat Clim Change News Views. https://doi.org/10.1038/ s41558-020-0756-6

Meyer-Gutbrod E, Greene C, Davies K (2018a) Marine species range shifts necessitate advanced policy planning: the case of the North Atlantic right whale. Oceanography. https:// doi.org/10.5670/oceanog.2018.209

Meyer-Gutbrod EL, Greene CH, Davies KTA (2018b) Marine species range shifts necessitate advanced policy planning: the case of the North Atlantic right whale. Oceanography 31:19-23

Miller DD, Ota Y, Sumaila UR, Cisneros-Montemayor AM, Cheung WWL (2018) Adaptation strategies to climate change in marine systems. Glob Chang Biol 24:e1-e14. https://doi.org/10.1111/gcb.13829

Miller KA, Munro GR, Sumaila UR, Cheung WWL (2013) Governing marine fisheries in a changing climate: a gametheoretic perspective. Can J Agric Econ 61:309-334. https://doi.org/10.1111/cjag.12011

Mustonen K, Mustonen T, Kirillov J (2018) Traditional knowledge of the northern waters. A regional report. Snowchange Cooperative

Mustonen T (2008) Interview notes with Yupiaq Educator Oscar Kawagley at the CBD 2008 Workshop Helsinki, Finland

Mustonen T (2009) Karhun väen ajast-aikojen avartuva avara. University of Joensuu, Joensuu

Mustonen T, Mäkinen A (2004) Pitkät hylkeenpyyntimatkat ja muita kertomuksia hylkeenpyynnistä (Long seal hunting trips and other narratives of seal hunting). Snowchange, Tampere

Mustonen T, Van Dam B (in press) Climate change and unalakleet: a deep analysis. Nat People

Nash K, Alexander K, Melbourne-Thomas J, Novaglio C, Sbrocci C, Villanueva C, Pecl GT (2020) Developing achievable alternate futures for key challenges during the UN decade of ocean science for sustainable development. Authorea. https://doi.org/10.22541/au.160166561. 14686672

Newman G, Wiggins A, Crall A, Graham E, Newman S, Crowston K (2012) The future of citizen science: emerging technologies and shifting paradigms. Front Ecol Environ 10:298-304. https://doi.org/10.1890/110294

Newman L et al (2019) Delivering sustained, coordinated, and integrated observations of the Southern Ocean for global impact. Front Mar Sci. https://doi.org/10.3389/fmars.2019. 00433

Norström AV et al (2020) Principles for knowledge co-production in sustainability research. Nat Sustain. https://doi. org/10.1038/s41893-019-0448-2 
O'Keefe CE, DeCelles GR (2013) Forming a partnership to avoid bycatch. Fisheries 38:434-444. https://doi.org/10. $1080 / 03632415.2013 .838122$

Ogier E et al (2020) Responding to climate change: Participatory evaluation of adaptation options for key marine fisheries in Australia's south east. Front Mar Sci 7:97

Oremus KL, Bone J, Costello C, García Molinos J, Lee A, Mangin T, Salzman J (2020) Governance challenges for tropical nations losing fish species due to climate change. Nat Sustain 3:277-280. https://doi.org/10.1038/s41893020-0476-y

Ottersen G, Melbourne-Thomas J (2019) Time to look forward to adapt to ocean warming. Proc Natl Acad Sci USA 6:201912639. https://doi.org/10.1073/pnas.1912639116

Payne MR, Hobday AJ, MacKenzie BR, Tommasi D (2019) Seasonal-to-decadal prediction of marine ccosystems: opportunities, approaches, and applications. Front Mar Sci 6:100

Pecl GT et al (2017) Biodiversity redistribution under climate change: impacts on ecosystems and human well-being. Science. https://doi.org/10.1126/science.aai9214

Pecl GT et al (2019a) Autonomous adaptation to climate-driven change in marine biodiversity in a global marine hotspot. Ambio. https://doi.org/10.1007/s13280-019-01186-x

Pecl GT et al (2019b) Redmap Australia: challenges and successes with a large-scale citizen science-based approach to ecological monitoring and community engagement on climate change. Front Mar Sci. https://doi.org/10.3389/ fmars.2019.00349

Pendleton LH et al (2019) Disrupting data sharing for a healthier ocean. ICES J Mar Sci. https:/doi.org/10.1093/icesjms/ fsz068

Pershing A, Mills K, Dayton A, Franklin B, Kennedy B (2018) Evidence for adaptation from the 2016 marine heatwave in the Northwest Atlantic Ocean. Oceanography. https://doi. org/10.5670/oceanog.2018.213

Pershing AJ et al (2019) Challenges to natural and human communities from surprising ocean temperatures. Proc Natl Acad Sci USA 116:18378. https://doi.org/10.1073/ pnas. 1901084116

Pinsky M, Mantua N (2014) Emerging adaptation approaches for climate-ready fisheries management. Oceanography 27:146-159. https://doi.org/10.5670/oceanog.2014.93

Pinsky ML, Reygondeau G, Caddell R, Palacios-Abrantes J, Spijkers J, Cheung WW (2018) Preparing ocean governance for species on the move. Science 360:1189-1191

Pinsky ML, Selden RL, Kitchel ZJ (2020) Climate-driven shifts in marine species ranges: scaling from organisms to communities. Ann Rev Mar Sci 12:153-179. https://doi.org/10. 1146/annurev-marine-010419-010916

Pinsky ML, Worm B, Fogarty MJ, Sarmiento JL, Levin SA (2013) Marine taxa track local climate velocities. Science 341:1239. https://doi.org/10.1126/science.1239352

Poloczanska ES et al (2013) Global imprint of climate change on marine life. Nat Clim Change 3:919-925. https://doi.org/ 10.1038/nclimate1958

Pomeroy R, Parks J, Mrakovcich KL, LaMonica C (2016) Drivers and impacts of fisheries scarcity, competition, and conflict on maritime security. Mar Policy 67:94-104. https://doi.org/10.1016/j.marpol.2016.01.005

Rassweiler A, Ojea E, Costello C (2020) Strategically designed marine reserve networks are robust to climate change driven shifts in population connectivity. Environ Res Lett 15:034030. https://doi.org/10.1088/1748-9326/ab6a25

Robinson E (2008) Closing words: go fish. In: Simpson L (ed) Lighting the 8th fire: the liberation, resurgence and protection of indigenous nations. Arbeiter Ring Publishing, Winnipeg

Scheffers BR, Pecl G (2019) Persecuting, protecting or ignoring biodiversity under climate change. Nat Clim Change 9:581-586. https://doi.org/10.1038/s41558-019-0526-5

Schwartz MW et al (2012) Managed relocation: integrating the scientific, regulatory, and ethical challenges. Bioscience 62:732-743. https://doi.org/10.1525/bio.2012.62.8.6

Shields JD (2019) Climate change enhances disease processes in crustaceans: case studies in lobsters, crabs, and shrimps. J Crustac Biol 39:673-683. https://doi.org/10.1093/jcbiol/ ruz072

Simpson L (2008) Lighting the 8th fire: the liberation, resurgence and protection of indigenous nations. Arbeiter Ring Publishing, Winnipeg

Smith DB et al (2020) Sharing our oceans fairly: improving international relations around ocean issues. Authorea. https://doi.org/10.22541/au.160441713.30169042/v1

Spijkers J, Boonstra WJ (2017) Environmental change and social conflict: the northeast Atlantic mackerel dispute. Reg Environ Change 17:1835-1851. https://doi.org/10. 1007/s10113-017-1150-4

Spijkers J, Morrison TH, Blasiak R, Cumming GS, Osborne M, Watson J, Österblom H (2018) Marine fisheries and future ocean conflict. Fish Fish 19:798-806. https://doi.org/10. 1111/faf.12291

Stephenson RL et al (2019) A practical framework for implementing and evaluating integrated management of marine activities. Ocean Coastal Manag 177:127-138. https://doi. org/10.1016/j.ocecoaman.2019.04.008

Stuart-Smith RD et al (2017) Assessing national biodiversity trends for rocky and coral reefs through the integration of citizen science and scientific monitoring programs. Bioscience 67:134-146. https://doi.org/10.1093/biosci/ biw 180

Sumby J, Haward M, Fulton EA, Pecl GT (2021) Hot fish: The response to climate change by regional fisheries bodies. Marine Policy 123:14284. https://doi.org/10.1016/j. marpol.2020.104284

Sunday JM, Bates AE, Dulvy NK (2012) Thermal tolerance and the global redistribution of animals. Nat Clim Change 2:686-690. https://doi.org/10.1038/nclimate1539

Tommasi D et al (2017) Managing living marine resources in a dynamic environment: the role of seasonal to decadal climate forecasts. Progress Oceanogr 152:15-49. https://doi. org/10.1016/j.pocean.2016.12.011

Tunon H (2018) Nordic IPBES like study of coastal ecosystems. Nordic Council of Ministers, Copenhagen

United-Nations (2015) Transforming our world: the 2030 agenda for sustainable development. UN Publishing, New York 
Wernberg $\mathrm{T}$ et al (2011) Impacts of climate change in a global hotspot for temperate marine biodiversity and ocean warming. J Exp Mar Biol Ecol 400:7-16. https://doi.org/ 10.1016/j.jembe.2011.02.021

Williams-Davidson T-L (2017) Out of concealment: supernatural female beings of Haida Gwaii. Heritage House, Vancouver
Publisher's Note Springer Nature remains neutral with regard to jurisdictional claims in published maps and institutional affiliations. 